\title{
A REPRODUÇÃO DA VIDA COTIDIANA NAS HABITAÇÕES URBANAS Rio de Janeiro e Porto no contexto pré-industrial
}

\section{THE REPRODUCTION OF EVERYDAY LIFE IN URBAN HOUSES Rio de Janeiro's and Porto's context before industrialization}

\author{
A. Julia M. Amaral \\ Universidade Federal Fluminense, Brasil \\ jmamaral@id.uff.br
}

\begin{abstract}
RESUMO
O trabalho sustenta que a organização espacial das habitações atende ao modo de reprodução da vida cotidiana e aborda essa relação nos casos particulares do Rio de Janeiro, até meados do século XIX, e do Porto, no século XVIII. Discute-se o cotidiano, com base na compreensão de Heller, enquanto categoria social e historicamente determinada cujas atividades, necessárias para a manutenção das estruturas sociais, são desempenhadas pelo indivíduo como ser particular e ser genérico a partir das assimilações pelas relações sociais. As habitações cariocas e portuenses nos fornecem um registro material de que a arquitetura se constitui em uma necessidade social, cujo espaço, entendido pela obra da Estética de Lukács, é uma expressão das necessidades práticas dos indivíduos e consiste em uma síntese de determinações econômicas, históricas e sociais.
\end{abstract}

Palavras-chave: cotidiano, espaço privado, trabalho.

Linha de Investigação: 1: Cidade e projeto

Tópico: 1. História urbana e história do urbanismo

\begin{abstract}
This paper sustains that the houses' organization of spaces reflects the reproduction system of everyday life and discuss its connection in particular cases such as Rio de Janeiro, until mid-19th century, and Porto, in 18th century. Based on Heller's comprehension, everyday life is examined as a social and historically determined category whose activities, which are required to maintain social structures, are performed by an individual as particular being and also as a generic one, based on assimilations by social relations. Both Rio de Janeiro's and Porto's houses shows us that architecture consists in a social need, whose space, according to Lukács' aesthetic theory, is an expression of individual's practical needs and it consists in a synthesis of economical, historical and social determinations.
\end{abstract}

Keywords: everyday life, private space, work.

Research line: 1: City and project

Topic: 1. Urban History and History of Urbanism 


\section{SÃO PAULO15 17 LISBOA $25 \sim 26$ JUN 2020

\section{Introdução}

O presente trabalho aborda o tema da cotidianidade para que se compreenda como as práticas cotidianas são parte do modo de reprodução social, e como o espaço principal de reprodução da vida cotidiana é produzido de modo a atender as necessidades práticas dos indivíduos. As cidades do Porto (Portugal) e Rio de Janeiro (Brasil), no contexto histórico em que as residências urbanas eram predominantemente constituídas por um híbrido funcional de habitação e local de trabalho, foram escolhidas para um breve estudo de caso que ilustre a relação entre a arquitetura e a vida cotidiana.

Parte-se da compreensão de Lukács (1965) e Heller (1985) sobre a categoria do cotidiano, para que se chegue ao momento particular em estudo que tem ênfase nas habitações da classe pequeno burguesa de ambas as cidades em um contexto anterior à sua industrialização a fim de compreender a relação entre a estrutura econômico-social, a vida cotidiana e a arquitetura.

Colocam-se as seguintes questões: o que caracteriza a vida cotidiana? Como suas esferas estão relacionadas com a individualidade e com o gênero humano? Como os elementos da vida cotidiana, em especial o trabalho, determinam padrões tipológicos e de organização espacial das habitações pequeno burguesas do Porto do século XVIII e do Rio de Janeiro do século XIX?

Para buscar responder essas questões foram examinadas obras de autores marxistas que lançaram luz sobre o cotidiano, como Georg Lukács e Agnes Heller, em 1965 e 1985, respectivamente, e que permitissem um aprofundamento teórico sobre essa categoria. Para a verificação das tipologias arquitetônicas foram realizados levantamentos de campo e pesquisas bibliográficas e iconográficas que permitissem compreender a estrutura espacial das casas portuenses e cariocas da época.

O olhar sobre esses estudos de caso se justifica por terem relações quanto à sua história. A história é entendida, segundo Heller (1985), como a própria substância da sociedade, que está em constante desenvolvimento. A substância de uma sociedade não pode estar contida em outro lugar senão nos indivíduos humanos que a constituem, pois são eles os portadores da objetividade social, ou seja, os responsáveis pela transmissão ou transformação das estruturas sociais. Essa substância - que não diz respeito a um único indivíduo, mas sim à sociedade - não pode ser confundida com essência humana, cujas componentes Marx define como o trabalho, a sociabilidade, a consciência, etc., ou seja, categorias que pertencem ao gênero humano. Embora tenha esse caráter a essência humana não é perene, mas, sim, histórica, e se define como a "realização gradual e contínua das possibilidades imanentes à humanidade" (Heller, 1985: 4), possibilidades essas que também são construídas socialmente. Portanto, a substância de uma sociedade contém a relação entre a essência humana e a sua estrutura social, que pode ser reproduzida ou transformada - o que caracteriza a história -, e se estrutura em esferas heterogêneas, como "produção, relações de propriedade, estrutura política, vida cotidiana, moral, ciência, arte, etc." (Heller, 1985: 3), historicamente determinadas e correspondentes às capacidades humanas.

Essa visão sobre a história nos permite compreender a colonização do território brasileiro como um choque entre as estruturas sociais dos povos originários e dos colonizadores, que eram profundamente distintas quanto às suas formas de sociabilidade e suas estruturas de produção, e, portanto, sua substância social. Tal embate é o gérmen desse modo de desenvolvimento histórico da sociedade brasileira, onde o processo da colonização garantiu a transmissão da substância da sociedade portuguesa enquanto as demais formas de 


\section{XII $\quad$ SÃO PAULO $15 \sim 17 \cdot$ LISBOA $25 \sim 26$ JUN 2020}

sociabilidade que existiam no território foram dominadas, o que está expresso na produção arquitetônica, na vida cotidiana e na estrutura social.

\section{A categoria do cotidiano}

No presente trabalho, o cotidiano assume centralidade, pois essa categoria constitui uma esfera de mediação entre o mundo econômico-social e a vida humana, estando no cerne do que se pretende desenvolver nesse estudo em relação a vida privada, o trabalho e a arquitetura. A reprodução da vida cotidiana nos informa sobre o indivíduo como ser social, que participa dela com todos os aspectos da sua individualidade, tais como sentimentos, habilidades manipulativas e ideologias, determinados segundo seu tempo histórico. "A vida cotidiana é a vida do indivíduo" (Heller, 1985: 20), que é sempre ser particular e ser genérico.

O decorrer da história está profundamente implicado na vida cotidiana, a qual é produzida a partir de necessidades e reflete as grandes mudanças desencadeadas pela humanidade:

"A vida cotidiana não está 'fora' da história, mas no 'centro' do acontecer histórico: é a verdadeira 'essência' da substância social. (...) As grandes ações não cotidianas que são contadas nos livros de história partem da vida cotidiana e a ela retornam." (Heller, 1985: 20)

É na esfera do cotidiano que os homens se adequam às formas sociais produtivas históricas. O indivíduo está inserido nela desde o seu nascimento e se mantém em constante processo de intercâmbio com seus grupos sociais. A assimilação da manipulação das coisas - desde as mais triviais que refletem aspectos elementares da cultura, como pegar um garfo, sentar-se à mesa, etc. - é sinônimo da assimilação das relações sociais, pois esse amadurecimento do indivíduo para a cotidianidade começa sempre por "grupos face-to-face" como a escola, a família, etc., "estabelecem uma mediação entre o indivíduo e os costumes, as normas e a ética de outras integrações maiores" (Heller, 1985: 19), ao mesmo tempo em que essas estruturas somente se reproduzem por meio das práticas cotidianas.

O amadurecimento do homem para Heller (1985) significa que o indivíduo adquiriu as habilidades necessárias para a garantia da sua própria reprodução na cotidianidade referente à camada social na qual está inserido. É a partir das relações sociais que o indivíduo se torna apto a viver na cotidianidade. Trata-se de incorporar às práticas cotidianas (nos elementos da cotidianidade) aquelas que foram aprendidas pelo indivíduo por meio de mediações com grupos sociais. Aprender a fazê-lo.

É a partir do "Eu", a partir de suas próprias necessidades, que o indivíduo assimila as necessidades humanas, mesmo que não compreenda de maneira consciente o que pertence ao genericamente humano, pois mesmo que desempenhadas por motivos particulares toda atividade tem caráter genérico. Assim, o trabalho, por exemplo, está tanto no nível da universalidade (humano-genérico), como atividade do gênero humano, quanto manifesto na particularidade (Eu individual), como motivação e necessidade individuais (Heller, 1985). Nesse movimento o indivíduo adquire consciência de si e da humanidade, pois encontra em suas necessidades o que o faz se reconhecer como humano.

De forma similar, os sentimentos e paixões pertencem ao gênero humano e são úteis para transmitir e expressar a substância humana, porém manifestam-se de maneira particular no indivíduo, que os coloca a serviço da satisfação de suas necessidades, necessidades do "Eu". Assim, o particular não é o sentimento 


\section{SÃOPAULO15 $17 \cdot$ LISBOA $25 \sim 26$ JUN 2020}

em si, mas o seu modo de manifestar-se. O humano-genérico jamais é representado por um homem sozinho, mas sempre pela "integração (tribo, demos, estamento, classe, nação, humanidade)" (Heller, 1985: 21), na qual o indivíduo forma sua consciência de si e da comunidade. Dessa forma, o indivíduo é um ser singular que está em relação com sua própria individualidade particular e com sua própria generidade humana:

"O indivíduo (a individualidade) contém tanto a particularidade quanto o humanogenérico que funciona consciente e inconscientemente no homem. (...) É comum a toda individualidade a escolha relativamente livre (autônoma) dos elementos genéricos e particulares (...) O homem singular não é pura e simplesmente indivíduo, no sentido aludido; nas condições da manipulação social e da alienação, ele se vai fragmentando cada vez mais 'em seus papéis'." (Heller, 1985: 22)

Portanto, a atividade individual do cotidiano, como o trabalho, nunca é completamente individual, pois se origina na projeção das necessidades de reprodução de uma classe social.

A vida cotidiana é heterogênea no que se refere ao conteúdo e significação das múltiplas atividades desenvolvidas em seu âmbito, que constituem suas partes orgânicas, como o lazer, o descanso, o trabalho, a organização da vida privada e o intercâmbio. A significação de tais partes se organiza de maneira hierárquica que varia em função das estruturas econômico-sociais. Logo, as atividades da vida cotidiana não são estritamente particulares (ou seja, próprias de determinado indivíduo), mas constituem atividades do gênero humano.

Esses aspectos da vida cotidiana possibilitam uma "explicitação normal" da produção e da reprodução dos indivíduos, não apenas no sentido material, mas também no que se refere às formas de intercâmbio. $O$ funcionamento da hierarquia espontânea é, para Heller (1985: 18), "necessário para que as esferas heterogêneas se mantenham em movimento simultâneo".

Toda e qualquer prática cotidiana tende à espontaneidade, que caracteriza tanto as formas particulares de atividade quanto as formas humano-genéricas - que estão também em toda atividade individual -, e se manifesta na efetivação do comportamento consuetudinário assimilado. Sem a espontaneidade não seria possível realizar nem mesmo uma fração das atividades cotidianas imprescindíveis pois nos tomaria grande parte do nosso tempo refletir sobre os conteúdos de cada uma delas. Assim, "tornar-se-iam impossíveis a produção e a reprodução da vida da sociedade humana." (Heller, 1985: 30)

Portanto, a espontaneidade do cotidiano é essencial para a reprodução da vida individual e em sociedade, posto que toda ação ou reflexão realizam-se apenas quando são imprescindíveis para o seguimento da cotidianidade, o que Heller (1985) chama de economicismo. O pensamento e a ação na cotidianidade formam uma unidade imediata, o que faz com que a atitude da vida cotidiana seja absolutamente pragmática. O pensamento cotidiano também é caracterizado pela ultra generalização, que consiste na subsunção do singular sob alguma universalidade, uma vez que na cotidianidade não há tempo para examinar os aspectos da singularidade, para garantir a continuidade da tarefa colocada. Assim, recorre-se à analogia, pois é nela que se cristaliza o conhecimento cotidiano do homem por meio da classificação em algum tipo já conhecido por experiência. A assimilação do sistema consuetudinário é realizada por meio da imitação, pois os indivíduos não agem meramente segundo seus próprios preconceitos, mas sim com base na repetição das ações dos outros. "Sem mimese, nem o trabalho nem o intercâmbio seriam possíveis." (Heller, 1985: 36). 


\section{SÃOPAULO15 $17 \cdot$ LISBOA $25 \sim 26$ JUN 2020}

Uma simples atividade que realizamos, como acender e apagar a luz, contém todas essas peculiaridades sobre o pensamento cotidiano: se tentássemos entender o circuito que ativa a lâmpada todas as vezes que acionamos o interruptor seria impossível acender ou apagar as luzes tal como fazemos no dia-a-dia.

Não existe vida cotidiana sem as formas aqui apresentadas - espontaneidade, economicismo, pragmatismo, ultra generalização, analogia e mimese -, que são necessárias à estrutura e ao pensamento cotidianos. Contudo, essa notória rigorosidade da estrutura da vida cotidiana não é absoluta, pois ainda pode ser produzida uma elevação sobre a cotidianidade para o desenvolvimento de outras atividades humanas, como a arte e a ciência, que dela partem e a ela tornam a influenciar. A partir do momento que essas formas se absolutizam e impedem uma margem de movimento, instaura-se a alienação da vida cotidiana (Heller, 1985). A própria reprodução do cotidiano pode trazer as demandas que exigem a sua transformação, como a inserção de novas tecnologias voltadas para o recuo das barreiras naturais. O cotidiano, não é, portanto, apenas reprodutibilidade e economicismo.

A estrutura e o pensamento da vida cotidiana estão diretamente ligados às atividades que garantem a reprodução material dos indivíduos e da sociedade, de acordo com as necessidades da camada social na qual se insere. Essa reprodução necessita de um suporte físico capaz de atender as demandas da reprodução cotidiana, como locais de descanso, trabalho, organização da vida privada e intercâmbio. No decorrer da história da vida privada destacam-se habitações que possuíam a peculiaridade de atender a essas demandas, que são mote do presente trabalho em um recorte temporal e espacial específico que discorreremos adiante.

Lukács considera que a arquitetura possui uma extraordinária sensibilidade como arte a respeito das transformações histórico sociais (Duayer, 2008), pois

"diferentemente das demais artes, 'cada sociedade, a partir de um certo nível evolutivo, tem que possuir sua própria arquitetura. Uma sociedade sem pintura ou sem tragédia é perfeitamente imaginável, e até existiu diversas vezes; mas não uma sem edifícios"' (Lukács, 1982: 131 como citado em Duayer, 2008: 15, tradução J. Duayer).

Portanto, a arquitetura configura-se em uma necessidade social que serve à reprodução material dos indivíduos ao mesmo tempo que é dotada de uma missão social determinada por seu caráter artístico (Duayer, 2008). Em outra parte de sua obra, para afirmar que o carácter artístico das construções habitacionais é suprimido para que prevaleça o seu caráter funcional, Lukács (1965: 171) utiliza uma citação de Bacon: "As casas são construídas para que se vivam nelas, não para serem contempladas". Portanto, as construções da vida cotidiana, as não excepcionais, são construídas de maneira a garantir a sua reprodução, sem uma vocação fundamentalmente estética. O modelo de solução da arquitetura dessas habitações particulares é sempre o resultado de uma "relação histórico social determinada e concreta que prevalece em cada caso entre o indivíduo e a classe (o estamento, etc.)" (Lukács, 1965: 141, tradução J. Duayer).

No caso das habitações é possível observar a contradição dialética estabelecida entre o socialmente geral (universalidade) e o pessoalmente privado (particularidade). Os postulados estéticos empregados pela consciência individual na criação de espaços destinados às tarefas da vida privada, para Lukács, dependem da imediatez da tarefa determinada socialmente. 


\section{SÃO PAULO15 17 LISBOA $25 \sim 26$ JUN 2020}

"As tarefas devidas a mera vida privada podem, sem dúvida, expressar desejos muito justificados desde o seu ponto de vista, mas sua convergência com as exigências estéticas de um espaço interno ou externo adequado para o homem será sempre de caráter casual." (Lukács, 1965: 142, tradução J. Duayer)

As construções privadas, portanto, priorizam o atendimento das tarefas que nelas serão desempenhadas, e a fruição estética torna-se casual. A conformação do espaço interno da habitação (e de maneira menos manifesta no espaço externo) corresponde a uma adaptação do espaço às necessidades práticas do indivíduo quanto às atividades que serão realizadas nele.

\section{A vida cotidiana nas habitações do Rio de Janeiro e do Porto}

Os objetos de estudo do presente trabalho, as habitações urbanas burguesas do Porto e do Rio de Janeiro, estão inseridos em um contexto histórico que se se caracteriza pelo predomínio do modelo econômico burguês de pequenos produtores e comerciantes, organizados em manufaturas com certo grau de especialização e divisão do trabalho. Essas habitações atendiam às necessidades das partes orgânicas da vida cotidiana, como o lazer, o descanso, o trabalho, a organização da vida privada e o intercâmbio.

O modelo híbrido de residência e comércio é predominante no meio urbano até a industrialização das cidades aqui em questão: no Porto até meados do século XVIII, quando surgiram as primeiras grandes indústrias de Portugal; no Rio de Janeiro até meados do século XIX, depois de uma paulatina transição do modo de produção baseado na exploração colonial e mão de obra escravizada para uma incipiente industrialização. As construções na tipologia arquitetônica aqui destacada, no entanto, não foram abandonadas após esse período, mas sim readequadas às novas demandas resultantes da transformação das estruturas sociais e do espaço urbano em expansão. Atualmente, nas duas cidades, as regiões caracterizadas pelo predomínio dessa tipologia são objeto de ações de proteção ao patrimônio por serem reconhecidas como registros de um momento particular do desenvolvimento histórico de ambas.

No decurso da colonização do Brasil a força de trabalho escravizada, que era predominante tanto no campo como na cidade, foi um elemento fundamental da vida econômica e social, inclusive na esfera privada, pois estava presente em grande parte do trabalho desenvolvido no interior dos domicílios, até mesmo os mais simples (Algranti, 1997). Especialmente no Rio de Janeiro, os negros escravizados eram responsáveis pelas tarefas domésticas, faziam parte da produção de mercadorias nas pequenas oficinas e também trabalhavam fora da casa, seja na venda de produtos ou no oferecimento de alguns serviços. Ao longo da colonização, pode-se notar um aumento na especialização dos ofícios nos centros urbanos, nos quais muitos produtos podiam ser adquiridos enquanto outros continuavam a ser produzidos para o próprio uso, em geral pelos escravos.

“(...) o trabalho permeou o cotidiano dos indivíduos e trouxe dinamismo ao interior dos domicílios, fosse ele dirigido para a subsistência e consumo dos moradores, fosse voltado para o mercado. Quando possível, grande parte das atividades desenvolveram-se nos anexos, aos quais já nos referimos, porém eles não impediam, devido à forma das construções, que as pessoas se encontrassem nos pátios internos e alpendres, nem a entrada e saída constante dos escravos." (Algranti, 1997: 151) 




\section{SÃO PAULO15 17 LISBOA $25 \sim 26$ JUN 2020 \\ Seminário Internacional de Investigação em Urbanismo \\ Seminario Internacional de Investigación en Urbanismo}

Essa tipologia com testada estreita e três, quatro ou mais pavimentos acima do térreo, se origina na necessidade de adensamento e "constitui um tipo híbrido funcional de residência urbana e estabelecimento comercial ao mesmo tempo, referidos à mesma família, estritamente utilitário, de acordo com as necessidades profissionais e a mentalidade da classe que lhe é própria" (Oliveira, Galhano, 1994: 279-280).

As lojas, armazéns ou oficinas localizavam-se junto à rua, no térreo, com acesso direto ao espaço público, enquanto os andares superiores serviam de residência. A estrutura interna da área residencial era formada por uma sala de visitas no primeiro andar, e quartos em alcova no segundo, ambos os andares com salas para a frente e para as traseiras. No terceiro andar, localizava-se a sala de jantar e cozinha, por razões de segurança devido aos incêndios. Os sótãos funcionavam como alojamento dos criados, arrumação e oratório. A escada percorria todos os andares e era iluminada por óculos ou claraboias, partindo de um átrio de azulejos (Oliveira, Galhano, 1994).

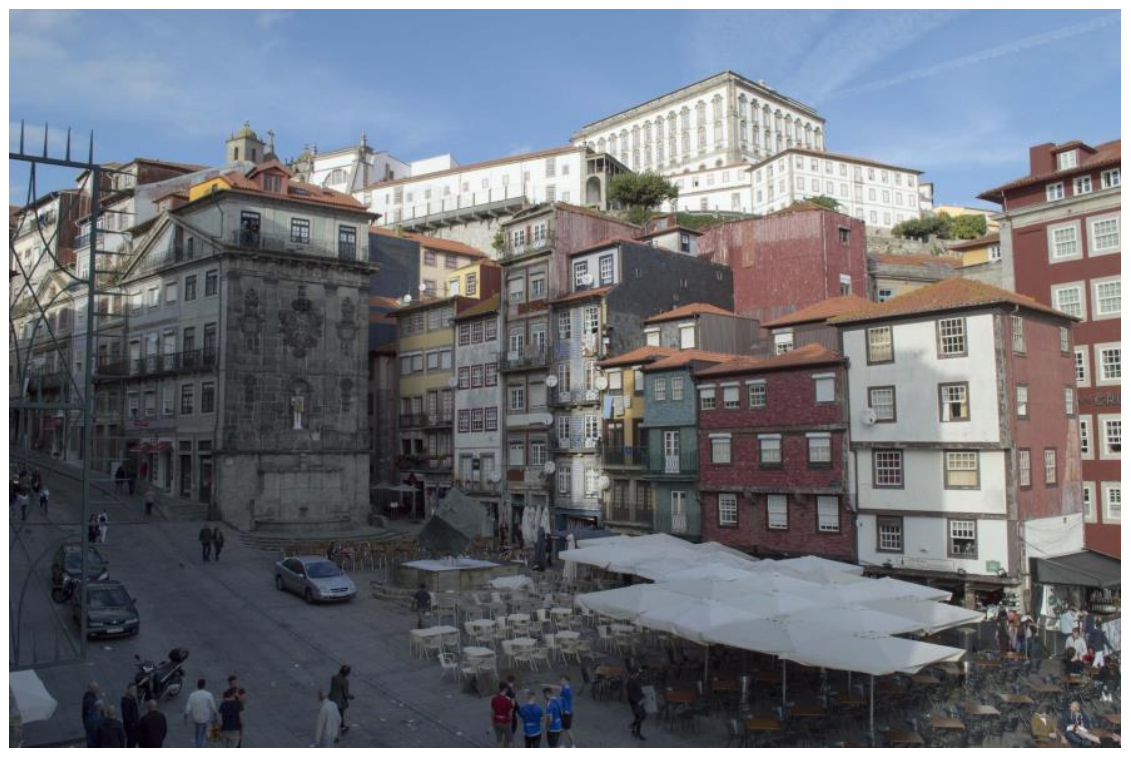

Fig. 05 Praça da Ribeira, no Porto, em outubro de 2019.

A semelhança entre as construções portuenses e cariocas, tanto em suas composições externas quanto nas suas estruturas internas, se origina nas adequações de uma tradição construtiva portuguesa oriunda das determinações históricas e sociais na qual estava inserida, em um novo território que se encontra sob outras determinações, mas que se mantém como forma de reprodução de esferas que estruturavam uma parte da sociedade portuguesa em particular. No caso brasileiro fez-se necessário adaptar a tradição trazida às demandas que aqui se faziam presentes.

\section{Conclusão}

As atividades do cotidiano são fundamentais para a manutenção da estrutura econômico-social e se realizam também, como no contexto apresentado, em espaços privados cuja organização atende às necessidades de reprodução da vida cotidiana dos indivíduos que neles habitam, conforme as demandas de sua camada ou classe social. Ao longo da história a arquitetura se configurou como uma necessidade social para a 


\section{SÃOPAULO15 $17 \cdot$ LISBOA $25 \sim 26$ JUN 2020}

reprodução material dos indivíduos, enquanto também é dotada de uma missão social determinada por seu caráter artístico. Contudo, ao passo que os espaços públicos se caracterizam tanto pela sua vocação artística e quanto pelo seu caráter prático, é essa segunda peculiaridade que prevalece nas construções privadas. Ao comparar o espaço privado com espaços destinados a uso público, Lukács diz:

"O espaço interior produzido pelo indivíduo privado no interesse de seus fins vitais imprescindíveis, e, portanto, necessariamente privados, tem primariamente muito menos a ver com um espaço suscitador de vivências. (...) O homem ativo nesse espaço - independentemente de que durma, ou trabalhe, etc., nele - utiliza o espaço e os objetos que o preenchem de um modo puramente prático no sentido da vida cotidiana, o qual, como mostramos em seu lugar, constata uma relação imediata entre a finalidade e o instrumento que a realiza." (Lukács, 1965: 144, tradução nossa)

Dessa maneira, é possível afirmar que a conformação do espaço interno das habitações privadas reflete os aspectos da estrutura e pensamento da vida cotidiana que remetem à utilidade prática imediata, e forma espaços igualmente pragmáticos, economicistas e baseados na imitação dos modelos de construção estabelecidos, o que se incorpora a uma prática arquitetônica, transformando-se em tradição. Nas habitações em estudo nesse trabalho, mas também em geral, a contemplação do espaço não assume centralidade nas escolhas sobre a sua organização. Porém, embora o caráter estético seja retraído diante da necessidade prática dessas construções, o espaço ainda pode ser preenchido por elementos destinados a promover a sua fruição, como ornamentos, entre outros. A principal finalidade dessas habitações é o atendimento às necessidades práticas de reprodução da cotidianidade, que se realiza em atividades do gênero humano, mesmo quando são desempenhadas individualmente, uma vez que toda atividade cotidiana contém o humano-genérico e é fundamental para a reprodução das estruturas sociais.

O modelo de solução da arquitetura privada é, portanto, resultado da relação histórico social entre o indivíduo e a classe à qual pertence, com conteúdo e função determinados preponderantemente por relações socioeconômicas e secundariamente pela individualidade dos que nela habitam. A padronização das construções pode ser assegurada por estruturas como leis e tradições, porém as tipologias e formas arquitetônicas só são reproduzidas porque atendem às demandas particulares da vida cotidiana dos indivíduos de uma classe. $\mathrm{Na}$ medida em que novas necessidades sociais surgem a arquitetura se transforma, visto que a humanidade não produz nada sem finalidade e utilidade para si mesma.

A vida cotidiana abriga os grandes acontecimentos da humanidade, que, por sua vez, partem da cotidianidade e a ela retornam. A arquitetura é um registro material dessas transformações, o que confere às construções privadas um caráter de registro das determinações histórico-sociais que as produziram. No Porto, as casas esguias refletiam o surgimento da classe burguesa que impulsionou a consolidação da vida urbana e atendia às necessidades de comercialização, produção e habitação. Sob determinações diferentes, mas com profundas ligações com a tradição construtiva portuguesa, no Rio de Janeiro os sobrados refletem a transformação introduzida pela formação dos núcleos urbanos na transição de um modo de produção de base agrícola para uma especialização da produção. Em ambos os casos se destaca a produção manufatureira, capaz de ser instalada nas dependências da residência devido à sua pequena escala. 


\section{SÃO PAULO15 17 LISBOA $25 \sim 26$ JUN 2020

O trabalho no interior das edificações, seja voltado para o abastecimento do mercado ou para a própria manutenção do lar, é uma atividade individual que corresponde aos interesses e as necessidades da classe. As atividades da vida cotidiana se organizam de maneira heterogênea e hierárquica, o que se reflete na organização espacial dessas habitações, nas quais o espaço é organizado segundo as atividades que serão nele desempenhadas. Essas habitações visavam atender as demandas por espaços de produção e comercialização, além do descanso, do intercâmbio e da organização da vida privada. A localização da loja no térreo, voltada para a rua, se justifica pela necessidade de facilitação do acesso direto e de criar uma transição entre o espaço público e o privado destinado aos membros da família. Os espaços de descanso correspondem ao mínimo necessário para que se revigore para o dia seguinte, já que o trabalho ocupava grande parte do cotidiano no interior das habitações. Os locais de produção de bens comerciáveis ou para o consumo doméstico também ocupam espaços determinados por necessidades práticas, sejam eles juntos ao local de armazenagem das mercadorias, ou nos fundos das habitações por questões de segurança e salubridade. Nas cidades aqui em estudo o máximo aproveitamento do espaço também caracterizou a forma das construções, que se justifica pelas limitações do espaço urbano, sejam elas impostas pelos muros no Porto ou pela pequena extensão da infraestrutura no Rio de Janeiro. Essa necessidade de adensamento reforçou a sobreposição de residência e comércio.

A vida cotidiana nas habitações em questão não atende apenas às necessidades de produção material, mas também as formas de intercâmbio e demais dinâmicas sociais, ligadas à convivência, a moral, a vida familiar, as tradições e a religiosidade. Os papéis desempenhados pelos indivíduos nas funções das residências e oficinas explicitam a classe à qual pertencem e demais determinações na qual estão inseridos. Havia uma diferença substancial entre as atividades desempenhadas pelos negros escravizados, pelas mulheres e pelos senhores no Rio de Janeiro, por exemplo, que revelam não só diferenças de raça e classe, mas que também explicitam a divisão sexual do trabalho.

Dentro das determinações do processo de urbanização do Brasil colônia estava a reprodução das esferas que compunham a substância social portuguesa para a constituição de uma nova sociedade que nascia sobre essas bases. Uma vez que a arquitetura constitui uma síntese de determinações econômicas, históricas e sociais, ela também foi uma estrutura material que produziu e foi produzida pela tentativa de dar continuidade às estruturas sociais portuguesas, que se juntaram às demais necessidades de produção $e$ reprodução que constituíram a sociedade brasileira. A arquitetura portuense não foi usada no Rio de Janeiro apenas como tradição ou modo de morar, mas porque também atendia às necessidades da reprodução do cotidiano e às limitações de infraestrutura da urbe carioca. Portanto, as atividades do cotidiano que encontram nas construções privadas o suporte para a sua reprodução, aqui representadas pelas habitações portuenses e cariocas de um momento histórico em particular, originam-se nos interesses e necessidades da classe social dos indivíduos que as habitam, para os quais a arquitetura e os objetos que a preenchem têm atribuições estritamente práticas que visam atender aos seus fins vitais e imprescindíveis.

\section{Bibliografia}

ALGRANTI, L. M. (1997). Famílias e vida doméstica. Em NOVAIS, F. A. e SOUZA, L. M. (Org.). Cotidiano e vida privada na América portuguesa (83 - 154). São Paulo: Companhia das Letras.

DUAYER, J. (2008). A arquitetura na Estética de Lukács. Revista Sinais Sociais/SESC (Rio de Janeiro), 3. 


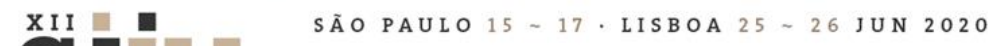

HELLER, A. (1985). O cotidiano e a história (C. N. Coutinho e L. Konder, Trad.). Rio de Janeiro: Paz e Terra.

LUKÁCS, G. (1965). Estetica, la peculiaridade de lo estetico: Tomo IV Cuestiones liminares de lo estético. (M. Sacristán, Trad.). Barcelona: Ediciones Grijalbo.

OLIVEIRA, E. V. e GALHANO, F. (1994). Arquitectura Tradicional Portuguesa. Lisboa: Publicações Dom Quixote.

REIS, M. C. B. N. (2013). O Porto e o comércio na segunda metade do século XVIII. A Companhia Geral da Agricultura das Vinhas do Alto Douro e os negócios do vinho (Tese de Doutoramento). Faculdade de Letras da Universidade do Porto, Porto, Portugal. Recuperado de https://repositorioaberto.up.pt/bitstream/10216/75501/2/31291.pdf (consulta: 15/02/2020). 